\title{
Mathematics Curriculum Change and Assessment Models: The Quest \\ for an Integrated Approach
}

\author{
Anyor, Joseph Wuave Ph.D and Abah, Joshua Abah \\ Department of Science Education \\ University of Agriculture Makurdi \\ Benue State, Nigeria.
}

\begin{abstract}
The mathematics curriculum is a plan for ordering and directing the teaching and learning of mathematics in educational institutions. A significant feature of the mathematics curriculum as an educational instrument is its ability to responds to the yearnings and aspirations of the people it serves. The recent change in the mathematics curriculum is targeted at realizing both present and future realities, by translating plans into achievable actions. However, the objectives of the curriculum will be missed if assessment practices are not reviewed and implemented. The existing psychometric model of assessment design which focused on standardized tests has failed to comprehensively cater for the needs of the students. This study seeks to unveil the inconsistencies and lack of guiding principles in assessment mechanisms in Nigeria. For the mathematics curriculum to be linked to rich assessment based on standards, the practice of assessing students' learning must be placed back into the hands of classroom teachers. An integrated approach is sought to efficiently combine various alternative assessment tools and resources, deriving evaluative feedback from students learning experiences for the purpose of enhancing mathematics instruction.
\end{abstract}

Keywords: Mathematics curriculum, Curriculum change, Assessment, Assessment models, Assessment instruments.

Recommended Citation

Anyor, J. W. \& Abah, J. A. (2014). Mathematics curriculum change and assessment models: The quest for an integrated approach. Benue Journal of Mathematics and Mathematics Education, 1(3), 11-19 


\section{Introduction}

The central dimension of every curricular effort is the classroom- involving students, teachers, school administrators, and the community. Thus, curriculum implementation is an interaction between those who have created the curriculum and those who are charged with the responsibility of delivering it. According to Ornstein and Hunkins (1998), implementation involves changes in the knowledge, actions and attitudes of people. These changes come through the practical application of a method, procedure or desired purpose.

Essentially, change is doing something differently. Change is a product of new knowledge occasioned by present realities and socio-cultural needs. In terms of providing a curriculum, nurturing a new culture in all facets of the educational community and encouraging continuous self-reflective growth and renewal for all stakeholders is the very nexus of change (New Jersey Mathematics Curriculum Framework, 1996). It is therefore obvious that change is a process and not just an event. It is also a fact that the Nigerian educational system has seen several phenomenal changes over the years. According to Ayeni and Dada (2011), these changes and innovations are to make the system relevant to the needs, yearnings and aspirations of Nigerians.

The most recent of these changes is the introduction of the Universal Basic Education (UBE) policy, launched in 2004. The UBE programme necessitated a curriculum change, which was actually a restructuring of the curricular framework to provide a compulsory and free 9- year basic education for every Nigerian child. This important milestone in the Nigerian educational landscape was born out of global concerns as expressed in the Millennium Development Goals (MDGs) and Education for All (EFA) policies of the United Nations (UN), and in the National Economic Empowerment and Development Strategy (NEEDS).

Given the unstable and consequently unreliable socio-economic realities in Nigeria, one cannot but wonder how far the UBE programme can go in meeting its target and achieving its sets objectives (Etuk, Ering, \& Ajake, 2012). One of the perceived areas of challenge, particularly in the implementation of the UBE mathematics curriculum, is assessment (Obioma \& Ajagun, 2006). The question of how thorough and effective a method of assessment is, is important for mathematics educators. This is because the 
output of periodic assessment is required for an extensive evaluation of the mathematics curriculum.

According to the Assessment Standards for School Mathematics of the National Council of Teachers of Mathematics (NCTM), assessment is the process of gathering evidence about a student's knowledge of, ability to use, and disposition toward mathematics, and of making inferences from that evidence for a variety of purposes (NCTM, 1995). Assessment goes beyond the restriction to evaluating individual student's performance at the end of instruction. Assessment is employed during the learning process to help teachers to monitor students' understanding and allow for adjustments of curriculum and instruction.

Various forms of assessment are available to educators today. But the reform measures encompassed in the 9- year UBE curriculum have thrown new challenges to establishing new assessment standards (Obioma \& Ajagun, 2006). The implication is that the basic priorities that necessitated the change in curriculum must be reflected in any model of assessment to be used in mathematics. For example, if the curriculum emphasizes entrepreneurship, then assessment strategies must seek to assess how students can apply mathematics proficiency in earning a living. If assessment must measure performance in line with the goals of education, then there must be a paradigm shift from mere acquisition of knowledge to application. There is a need to assess not just the cognitive aspect of mathematics but the whole of the subject.

\section{Overview of the Mathematics Curriculum in Nigeria}

Alade (2011) sees curriculum as the medium through which educational institutions seek to translate societal values into concrete reality. Curriculum is the foundation of the entire teaching-learning process, whether it is a formal school or an informal training setup. Since it is the plan for ordering and directing the instructional experiences that students encounter in an educational institution, there can be no educational training without curriculum.

It is therefore obvious that curriculum is an indispensable tool of education. Etuk et al (2012) observed that education itself is the process of acquiring new values and skills for 
the purpose of effective functioning in the society. Education, along with its pivotal curriculum development process, occupies an important position in Nigeria. National interests in this system that leads to the maturing of young people, has led to a peculiar dynamism in curricular efforts in the country.

Before the arrival of western education in Nigeria, the pre-existing traditional educational system was purely informal. The undocumented curriculum of this era is tailored towards the inculcation of productive ability in learners to enhance self-support. Under this apprenticeship system, the trainee acquires skills, values, and attitudes to allow for proper integration into the larger society.

Introduction of a formal curricular instrument came with the arrival of colonial missionaries towards the end of the first half of the nineteenth century (i.e. around 1842). The western-style primary schools provide instructions in Reading, Writing, Arithmetic and Religion. Thus, the Arithmetic curriculum became the first generation mathematics curriculum in its rudimentary form, in Nigeria.

Ajayi (1963) (cited in Alade, 2011) related that several societal factors led to a review of the Arithmetic curriculum giving birth to Geometry and Trigonometry, both subsistence components of mathematics. These were taught in the Grammar and High Schools from 1859 onward. Further development results in the introduction of Core Mathematics and Applied Mathematics between 1910 and 1925. These early curricular efforts were heavily dependent on the British system of education.

After Independence, diverse recommendations from cross-sections of Nigerian educationist and the pertinent issues raised by the pre-independence Ashby Commission led to the National curriculum Conference in 1969. This conference formed the basis for the drafting of the National Policy on Education (NPE).

Considering the inconsistencies of the British-type academic curriculum and nonreflection of existing realities, the former Western Region introduced the Universal Primary Education (UPE) scheme in 1955 (Yusuf \& Ajere, 1999). The UPE came with a new mathematics curriculum, which differs significantly from previous ones. The Eastern Region joined the UPE train in February 1957. 
The formal launching of the UPE as a national programme in 6th September, 1976, underscores the emerging paradigm to education in Nigeria. The launch was followed immediately by the publication of the National Policy on Education (NPE) in 1977. The UPE basically advocates a 6-3-3-4 system of education.

The UPE curriculum is aimed at permanent literacy and numeracy, and effective communication. The UPE mathematics curriculum emphasized understanding of mathematics as it relates to other field of study. Themes in this great instrument were spread over the general areas of Number and Numeration, Basic Operations, Measurement, Algebraic Process, Mensuration and Geometry, and Statistics. The elements of the UPE curriculum are so fundamental that they formed the bedrock for subsequent changes, review and improvement.

Curriculum has been described as a dynamic, intellectual and social enterprise (Onyeleke \& Akinyeye, 2013). The implication is that it is highly responsive to the needs and challenges of the people it is meant to serve.

The Universal Basic Education (UBE) was launched in 1999 by the Federal Government in response to the Declaration on Education for All (EFA) as recommended by the Jomtien Conference of 1990. The implementation of the new basic education mathematics curriculum, which is for 9 years continuous schooling, commenced in September 2008 in all Primary and Junior Secondary Schools in Nigeria (Awofala, OlaOluwa, \& Fatade, 2012). Basically, the new curriculum was necessitated by the need to encourage innovative teaching approaches and learning approaches that promotes creativity and critical thinking of learners (NERDC, 2012). There is also the need to touch on issues of national interest such as gender sensitivity, globalization, environmental preservation, HIV/AIDS and family life.

A distinguishing feature of the 9- year Basic Education Mathematics Curriculum is he emphasis placed on affective domain and quantitative reasoning in order to "boost learners' cognitive and psychomotor capabilities" (NERDC, 2012. p. vii). It also provided maximal aid for teaching by prescribing topics, expected learning outcomes, students and teachers activities and evaluation guides. Broad themes represented include Number and Numeration, Basic Operations, Measurement, Practical and Descriptive Geometry, Everyday Statistics, and Elements of Computer Operations. 
Specifically, the objectives of the curriculum are as follows.

To provide learners the opportunity to:

1. Acquire mathematical literacy necessary to function in an information age.

2. Cultivate the understanding and application of mathematics skills and concepts necessary to thrive in the ever changing technological world.

3. Develop the essential element of problem solving, communication, reasoning and connection within the study of mathematics.

4. Take advantage of the numerous career opportunities provided by mathematics.

5. Become prepared for further studies in mathematics and other related fields. (NERDC, 2012. p. vi).

The sensitive restructuring and realignment that resulted in the current curriculum confirms the fact that for any educational system to adequately respond to the challenges of education for the sustainable development of a society, a virile, dynamic and living curriculum is very significant.

\section{The Need for an Assessment Standard in Mathematics}

The online Merriam-Webster Dictionary defines assessment as the act of making judgment about something or somebody. It can be seen as the systematic appraisal, collection, review and use of information about educational efforts to improve students learning. Assessment is the process of observing and measuring learning (Slattery, 2013).

Assessment is the educational practice of identifying, gathering and interpreting information about students' learning. The central purpose of assessment is to provide usable data on student achievement and progress in order to monitor the flow of ongoing teaching and learning. Davies (2013) opines that the aim of classroom assessment is to support student learning and to communicate that learning to others. In order to support student learning, assessment needs to involve students deeply in the evaluative process, provide feedback during the learning, and include concrete feedback as required to report 
progress over time. This helps build a shared language that everyone can use to describe growth and learning.

Using different forms of assessment during the learning process enables students to have clearer vision of what is expected of them and generally will be more positive about their educational experience (Slattery, 2013). Davies (2013) submits that in classroom assessment, teachers review evidence of learning from three different sources, namely, observations of students engaged in learning, conversations with students about their learning, and reviewing their products (i.e. notebooks, tests, class works, projects, assignments and quizzes). Students' learning is measured against the learning goals. It is thus a basic requirement that teachers identify the level of quality of their work appropriate for the topic or class.

Educational assessment has erroneously been made synonymous with standardized testing. Van den Heuvel-Panhuizen and Becker (2003) pointed out that the dynamic growth in school testing was no doubt stimulated by the development and popularization of ability and intelligence testing. Over the years, test-driven instruction, in association with the criterion-referenced tests that assessed whether students had achieved particular attainment objectives, became very common. It became the norm for educational institutions to jostle for superiority based on performance of students in standardized national examinations. Local, state and federal education authorities often make illinformed judgments based on summative evaluation results obtained at the end of the Upper Basic level and Senior Secondary level. The error, according to Ubong and Wokocha (2009), is the departure from sustained evaluation intended for early detection of problem areas that each student encounters with a view to designing and implementing corrective measures for them.

Heralding the call for establishing new assessment standards, Obioma and Ajagun (2006) posited that standards often describe expectations of skills, knowledge competencies and behaviour needed by learners to perform at high levels. Assessment standards are expected to provide quality assurance in the practice of evaluation. What is obvious across Nigeria today is a wanton proliferation of diverse assessment mechanisms, an indication of the half-hearted attention and lips service paid to the fundamental dogma of educational assessment. With the scale tilting in favour of private educational ventures, it 
is not uncommon to find schools derailing from current best practices. The state of assessment practices in Nigeria only point to the unhealthy lack of guiding principles.

If the core tenets of mathematics curriculum must be followed there is an urgent need to revisit existing views of assessment in the Nigerian educational system. The very challenges in the practice of assessment which necessitated the introduction of continuous assessment (CA) in the 1980's are beginning to resurface in recent times. Emphasis on paper qualification obtained in one-shot examinations is replacing the culture in which the overall portrait of a pupil's performance can be presented more reliably, more comprehensively and more systematically (Atsumbe \&Raymond, 2012). The CA system, after a mere three-decade lifetime, has become moribund and bedeviled by several astute inconsistencies. The results of a large-scale survey across the six geopolitical zones of the country has indicated the sorry state of CA practices demonstrated by primary and junior secondary schools teachers (Obioma, 2008). The survey particularly revealed that:

CA guidelines varied across schools and were inappropriately applied. Only a monotony of class tests was used at intervals not even regular. Other CA instruments such as practical work, anecdotes, observation and sociometry that could illicit non-cognitive information were hardly applied. (Obioma, 2008. p. 6)

Atsumbe and Raymond (2012) attested that there is lack of uniform standards in the implementation of assessment across several schools. Some schools are known for maintaining higher standards than others. Such schools often subject students to tests that are grossly above their level, creating a situation whereby students study mainly for passing their examinations, without internalizing the learning experience. These discrepancies call for a harmonization of standards in the practice of assessment in the country.

For students to be career ready, all key stakeholders need to understand how mathematical practices will be assessed (Consortium for Mathematics and its Application, 2011). Measurement of mathematical practices such as problem solving, reasoning, connection, communication, conceptual understanding, and procedural fluency must be a salient feature of assessment design and task creation. It is therefore imperative that the mathematics curriculum be linked to rich assessment based on standards. 


\section{Basic Considerations for Assessment Models}

Assessment of students learning has remained the centerpiece of many educational reforms (Obioma \& Ajagun, 2006). The National Council of Teachers of Mathematics (2000) maintained that assessment should support the learning of important mathematics and furnish useful information to both teachers and students. It should inform and guide teachers as they make instructional decisions. Feedback from assessment exercise aids students in setting goals, assuming responsibility for their own learning and becoming more independent learners.

It is important to note that as mathematics curriculum and teaching is being reformed, assessment also needs to be reformed. Van den Heuvel-Panhuizen and Becker (2003) observed that currently, standardized tests are based on a psychometric model of assessment design in mathematics education, and this approach differs significantly from the model of assessment design that is more closely connected to a domain-specific theory of education. Standardized tests are limited in both their mathematics and the opportunities they provide classroom teachers to evaluate students understanding.

The acceptable concept of assessment practice is for a classroom teacher to construct and implement his or her own assessment, and then make evaluative decisions based on the results (Atsumbe \& Raymond, 2012). However, today, these same classroom teachers are subjected to an enormous focus on standardized testing, often determined by their local, state, regional or national government agencies (Van den Heuvel-Panhuizen and Becker, 2003). Since results of national assessments are widely published, teachers, schools and whole local education efforts are being assessed. As a direct consequence, teaching to test has become common. In the long run, there is a narrowing of the curriculum at the classroom level to the domain of mathematical content covered by the tests.

Appropriate assessment models must take cognizance of the goals of mathematics education. A good assessment should ask what mathematical ideas are important, how mathematics is learned, how mathematics is being taught, and what its applications are in real life situations. Suggesting an assessment framework at the end of the $32^{\text {nd }}$ Annual Conference of the International Association for Educational Assessment (IAEA), officials 
of the Nigerian Educational Research and Development Council (NERDC) submitted that a carefully conceptualized National Assessment Framework (NAF) should contain:

1. explicit statements about the purposes that the assessment will serve;

2. descriptions of the substance and technical quality of the skills, knowledge, etc, being assessed for classroom-based learning;

3. clear descriptions of relationships between assessment information and decisions that could be taken;

4. description of data collection method, including varieties of instruments and sources of data that should be used;

5. internal consistency measures and procedures;

6. descriptions of the method for data interpretation; and

7. descriptions of the decisions that could be made including who will make the decisions and by what procedures. (Obioma \& Ajagun, 2006. pp 9-10).

This beautiful blueprint for national standards for assessment has suffered implemention challenges several years after, as confirmed by the Chief Executive of NERDC elsewhere (Obioma, 2008).

It is obvious that only a little effort is being put into the core values of classroom assessment by Nigeria's educational authorities. The focal point of all diversions from valid practice of assessment is the over-emphasis on statewide and nationwide pencil-topaper tests. Such overt valuation of a one-shot assessment has resulted in student boredom and gradual extinction of mathematics culture. The downward movement of mathematical vigor will continue, except educational regulatory agencies stand up to the task and propagate the idea that assessment be placed back into the hands of teachers.

\section{A Call for an Integrated Approach}

An all inclusive assessment should be linked to the instruction and to school mathematics as the subject matter, and in principle, is part of the teacher's daily educational practice (Van den Heuvel-Panhuizen and Becker, 2003). The prevailing psychometric approach to 
assessment tends to assess only the answers to mathematics problems. An integrated approach seeks to combine existing models of assessment design with more intensive alternative assessment strategies. The goal is to present an approach that is interested in both the procedures and the answer of mathematical problems.

A variety of assessment instruments should be used to enable the teacher monitor student's progress in understanding mathematical concepts and in developing mathematical skills (New Jersey Mathematics Curriculum Framework, 1996). Obioma (2008) listed such instruments to include test, claasswork, homework, project, observation, sociometric technique, interview, questionnaire report, anecdotal report, checklist, rating scale, inventory and practical work. The focus of integrating various assessment tools is to ensure that mathematical learning is not confined to intermittent standardized tests. The learning environment should enable assessment as a way of improving learning, being a routine part of ongoing classroom activity rather than an interruption.

The following major assessment instruments are described briefly, based on insights provided by Stenmark (1991) (as cited in New Jersey Mathematics Curriculum Framework, 1996).

1. Individual and Group Tests: These are traditional paper-and-pencil testing, comprising of selected-response items - such as matching, multiple-choice, and true/false questions. Constructed-response items may contain problems to solve, short-answers, fill in the blank or "show your work" questions. Tests instruments should address the ability of students to form and communicate mathematical ideas and arguments, see and make connections between the various aspects of mathematics.

2. Authentic Performance Tasks: The administration of this instrument starts with asking a student or group of students to engage in some mathematical task or investigation. For instance, a teacher can ask students "how many bicycles are there within two kilometers of this school?" Here the teacher will have them make a plan for investigating the question and prepare an oral report. Another authentic performance task can be in the form "if you measured your desk with five 
different rulers and got five different answers, how would you decide which answer was correct?" Tasks used here must be rich and motivating.

3. Portfolios: A portfolio is a showcase of student work. It is a place where students can demonstrate their mathematical power in specific and general ways. A student's portfolio can contain table of contents, introductory and self assessment letters, long term projects, daily notes, mathematical models of real world phenomena and a mathematical autobiography. Other items include scale drawings, photographs, homework, self-generated problems and solutions, group projects, excerpt from team notebooks, etc. Teachers work with students to regularly review their portfolios in order to establish short-term and long-term goals.

4. Journals: A journal is a small booklet or notebook sections in which students write on a regular basis. The entries can be a daily part of the math class, with students responding to a writing prompt from the teacher, or very free, with the students choosing their own math topic and question to write about. A journal prompt may appear as "why do you think completing the squares is more tasking than factorization, in solving quadratic equations?" To enhance free communication of ideas, journal entries are not graded.

5. Observations, Interviews, and Conferences: These means provide teachers and students with numerous opportunities to assess progress. A student can analyze his or her own mathematical work by focusing on the quality of the product, the need for revision, changes or additions to be made, and different problem-solving strategies to employ.

6. Seminars, Labs, and Extended Projects: These methods are especially appropriate for assessing students' ability to identify and define a problem and what they already know; to make a plan; to discuss, review, revise, and explain results; to persist in work on a problem; and to produce a quality product or report. Projects can vary from creating a logic puzzle to providing status reports on starting a small scale business.

7. Visits: Field trips to places relevant to applications of mathematical concepts can be arranged and assessed 
Other tools of assessment include anecdotal records which are systematically kept notes of specific observations of student behaviors, skills, and attitudes in the classroom. Anecdotal records provide cumulative information regarding progress, skills acquired, and directions for further instruction. Systematic collection of anecdotal records on a particular student provides excellent information for evaluation of learning patterns and consistency of student progress.

Checklists, rating scales, and rubrics are assessment tools that state specific criteria that allow teachers and students to make judgments about developing competence. Checklists usually offer a yes/no format in relation to the specific criteria and may be directed toward observation of an individual, a group, or a whole class. Rating scales allow for an indication of the degree or frequency of the behaviours, skills and strategies, or attitudes displayed by the learner. Rubrics are an expanded form of rating scale that list several specific criteria at each level of the scale.

The integrated approach to assessment derives its power from the flexibility available to both mathematics teachers and students. It encourages creativity and critical thinking. By assessing students on the go, the teacher stimulates students and gradually eliminates the phobia associated with the administration of tests. Moment-to-moment decisions about instruction can be taken as mathematics teachers listen to students while they are engaged in ordinary classroom activity.

\section{Conclusion}

On-going educational reforms have thrown new challenges for setting assessment standards that will strategically map out criteria for quality assurance (Obioma \& Ajagun, 2006). These challenges can only be handled by going back to the basic foundation of educational assessment. Assessment must be aligned with curriculum and instruction, deriving inferences from multiple sources of evidence. It should be a collective effort which regards students as active participants in the assessment process.

Internal accountability must precede external accountability. Just like Van den HeuvelPanhuizen and Becker (2003) proposed, school personnel need to share a coherent, explicit set of norms and expectations about what good school should be. The 
fundamental principles of assessment must be adhered to with the aim of improving students learning. This piece of work does not suggest abandoning of standardized tests altogether, but has attempted to make a case for the inclusion of alternative assessment strategies in the design and implementation of classroom assessment. Educational regulatory agencies should implement assessment standards in mathematics, considering the growing importance of the subject. The gap in communication between ministries of education and classroom teachers must be bridged to enhance the execution of current best practices in mathematics assessment.

\section{References}

Alade, I. A. (2011). Trends and Issues on Curriculum Review in Nigeria and the Need for Paradigm Shift in Educational Practice. Journal of Emerging Trends in Educational Research and Policy Studies (JETERAPS), 2(5), 325-333

Atsumbe, B. N. \& Raymond, E. (2012). Problems of Implementing Continuous Assessment in Primary Schools in Nigeria. Journal of Education and Practice, 3(6), 71-76

Awofala, A. O. A.; Ola-Oluwa, S. A. \& Fatade, A. O. (2012). Teachers' Perception of the New Nine-Year Basic Education Mathematics Curriculum in Nigeria. International Journal of Mathematics Trends and Tecnology, 3, 1-6. Retrieved on $13^{\text {th }}$ December, 2013, from http://www.internationaljournalssrg.org

Ayeni, M. A. \& Dada, M. A. (2011). An Exploration into the Education Innovations in Nigeria in the Last Two Decades. Journal of Emerging Trends in Educational Research and Policy Studies (JETERAPS) , 2(4), 199-205

Consortium for Mathematics and Its Application (2011). Moving Forwards Together: Curriculum \& Assessment and the Common Core State Standards for Mathematics. Pentagon City, VA: COMAP Inc. 1-17

Davies, A. (2013). Assessment for Learning: Making Classroom Work. Retrieved on $14^{\text {th }}$ December, 2013, from http://annedavies.com/assessment_learning_wafl.html

Etuk, G. R., Ering, S. O. \& Ajake, U. E. (2012). Nigeria's Universal Basic Education (UBE) Policy: A Sociological Analysis. American International Journal of Contemporary Research, 2(7), 179-183

Merriam-Webster Dictionary (2013). Assessment - Definition. Retrieved on $14^{\text {th }}$ December, 2013, from http://www.merriam-webster.com/dictionary/assessment 
National Council of Teachers of Mathematics (2009). Executive Summary: Principles and Standards for School Mathematics. Reston, VA: National Council of Teachers of Mathematics. 1-6

National Council of Teachers of Mathematics (2009). Guiding Principles for Mathematics Curriculum and Assessment. Reston, VA: National Council of Teachers of Mathematics. 1-5

NERDC (2012) The 9-Year Basic Education Curriculum (Mathematics). Lagos: NERDC Printing Press. pp iii-xi

New Jersey Mathematics Curriculum Framework (1996). Trenton, NJ: New Jersey State Department of Education. 593-666

Obioma, G. (2008). Continuous Assessment Practices of Primary and Junior Secondary School Teachers in Nigeria. Retrieved on $17^{\text {th }}$ Decemeber, 2013, from http://iaea2008.cambridgeassessment.org.uk/ca/digitalAssets/164837_Obioma.pdf

Obioma, G. \& Ajagun, G. A. (2006). Establishing New Assessment Standards in the Context of Curriculum Change. A paper presented at the $32^{\text {nd }}$ Annual Conference of the International Association for Educational Assessment (IAEA) held at the Grand Copthorne Hotel, Singapore, on May 21-26, 2006. 2-11

Onyeleke, O. \& Akinyeye, C. O. (2013). Curriculum Development in Nigeria: Historical Perspective. Journal of Educational and Social Research, 3(1), 73-80

Ornstein, A. \& Hunkins, F. (1998). Curriculum: Foundations, Principles and Issues. Boston, MA: Allyn \& Bacon.

Slattery, W. (2013). Assessment. Retrieved on $14^{\text {th }}$ December, 2013, from http://serc.carleton.edu/introgeo/assessment/index.html

Ubong, B. and Wokocha, M. (2009). Continuous Assessment, Practicum, and the Quality of Business Education Programmes in Nigeria. Review of Higher Education in Africa, 1(1) Retrieved on $25^{\text {th }}$ April, 2013, from http://journal.lib.uoguelph.ca/index.php/rhea/article/view/1526/2232

Van den Heuvel-Panhuizen, M. \& Becker, J. (2003). Towards a Didactic Model for Assessment Design in Mathematics Education. In A. J. Bishop, M. A. Clements, C. Keitel, J. Kilpatrick \& F. K. S. Leung (Eds.), Second International Handbook of Mathematics Education, 689-716. Dordrecht: Kluwer Academic Publishers.

Yusuf, A. \& Ajere, R. O. (1999). Universal Basic Education (UBE) in Nigeria. Retrieved on $11^{\text {th }} \quad$ December, 2013, from http://www.musero.org.ng/publications/UNIVERSAL-BASIC-EDUCATION(UBE)-IN-NIGERIA.pdf 